\title{
First Revision of the German S3 Guideline 'Diagnosis, Therapy, and Follow-Up of Breast Cancer'
}

\author{
Achim Wöckel Rolf Kreienberg for the experts of the German S3 guideline* \\ Universitätsfrauenklinik Ulm, Medizinische Fakultät und Universitätsklinikum Ulm, Germany
}

Key Words

Breast cancer · Guideline · Diagnosis · Therapy · Follow-up

\section{Summary}

The development and implementation of evidencebased, interdisciplinary, consensus-based guidelines is a very important step towards decreasing breast cancer mortality and optimizing the process of early detection, diagnosis, therapy, and follow-up of breast cancer. A revised version of the German S3 guideline was published in February 2008. Different working groups, departments, and organizations participate as coeditors of the new guideline. To fulfill international methodic requirements, a systematic search of the literature with selection of new publications (used as evidence) in the established data bases (Medline, BIOSIS, Previews, CDSR, ACP Journal Club, DARE, CCTR, CINHAL) and the Guidelines International Network (GIN) was performed for the time period of 2003-2006. Varied specialist opinions concerning diagnosis, therapy, and follow-up of breast cancer were considered in formal consensus processes. In different steps, Nominal Group Process techniques, the Delphi technique, and formal consensus processes were used. Besides differently weighted, study-based recommendations, statements resulting from structured consensus finding by the interdisciplinary group - in terms of good clinical practice - were postulated.

\section{Schlüsselwörter:}

Brustkrebs · Leitlinien · Diagnose · Therapie · Nachsorge

\section{Zusammenfassung}

Die Entwicklung und Implementierung von evidenz- und konsensusbasierten, interdisziplinären Leitlinien ist ein effektiver Beitrag zur Senkung der Brustkrebsmortalität und Optimierung des Prozesses der Früherkennung, Diagnose, Therapie und Nachsorge beim Mammakarzinom. Eine aktualisierte Version der deutschen S3-Leitllinie wurde im Februar 2008 publiziert. Verschiedene wissenschaftlich-medizinische Fachgesellschaften, Arbeitsgruppen und Organisationen konnten die Überarbeitung realisieren. Um international geforderte methodische Kriterien zu erfüllen, wurde primär eine systematische Literaturechereche in etablierten medizinischen Datenbanken (Medline, BIOSIS, Previews, CDSR, ACP Journal Club, DARE, CCTR, CINHAL) und dem Leitlinienregister Guidelines International Network (GIN) veranlasst, um aktuelle und methodisch hochwertige Publikationen als Evidenzgrundlage zu identifizieren. Der Suchzeitraum erstreckte sich von 2003 bis 2006. Das Datenmaterial und die Expertenmeinungen wurden über strukturierte Konsensusprozesse zusammengeführt. Zum Einsatz kamen Techniken des Nominalen Gruppenprozesses (NGP), Delphi-Techniken und formale Konsensusprozesse. So konnten neben studienbasierten Empfehlungen auch Statements im Sinne einer "good clinical practice» formuliert werden.

*U. Albert, H.H. Bartsch, M.W. Beckmann, D. Berg, U. Bick, A. du Bois, W. Budach, J. Dunst, J. Engel, B. Ernst, M. Geraedts, U. Henscher, D. Hölzel, C. Jackisch, K. König, I. Kopp, H. Kreipe, T. Kühn, A. Lebeau, S. Leinung, H. Link, H.J. Lück, H. Madjar, A. Maiwald, G. Maiwald, N. Marschner, M. Marx, G. von Minckwitz, I. Naß-Griegoleit, K. Possinger, A. Reiter, W. Sauerbrei, W. Schlake, R. Schmutzler, I. Schreer, H. Schulte, K.D. Schulz †, R. Souchon, C. Thomssen, M. Untch, U. Wagner, J. Weis, T. Zemmler.

\begin{tabular}{ll}
\hline KARGER & @ 2008 S. Karger GmbH, Freiburg \\
Fax +49 7614520714 & Accessible online at: \\
$\begin{array}{l}\text { E-mail Information@Karger.de } \\
\text { www.karger.com }\end{array}$ & www.karger.com/brc
\end{tabular}

Dr. Achim Wöckel

Universitätsfrauenklinik Ulm

Medizinische Fakultät und Universitätsklinikum Ulm

Prittwitzstraße 43, 89075 Ulm, Germany

Tel. +49 731 500-58566, Fax -58686

E-mail achim.woeckel@uniklinik-ulm.de 


\section{Introduction}

Breast cancer continues to be the most frequent cancer in women. In Germany, almost 55,000 women per year are diagnosed with breast cancer, and about one third of the affected women die per year [1]. For that reason, the focus of science and healthcare policies is to decrease breast cancer mortality, and to optimize the process of early detection, diagnosis, therapy, and follow-up, in combination with preservation or even improvement of quality of life. Therefore, the development and implementation of evidenced-based, interdisciplinary consensus-based guidelines is a very important step towards achieving that goal [2]. Guidelines should support both clinicians and patients in medical decision-making, and should improve the afore-mentioned sequence (early detection, diagnosis, therapy, and aftercare) according to the individual disease, be it a primary, recurrent or metastatic course.

The first version of the $\mathrm{S} 3$ guideline of breast cancer according to the standards of the guideline manual of the 'Arbeitsgemeinschaft wissenschaftlich medizinischer Fachgesellschaften (AWMF)' and the 'Ärztliches Zentrum für Qualität in der Medizin (ÄZQ)' was published in 2004 [3, 4]. At this point, a systematic research, selection, and evaluation of literature with regard to care-relevant issues had already been undertaken. For this purpose, studies and recommendations were classified predicated on evidence-based medicine, until a consensus with the experts of all participating departments was found. To provide explicit management instructions for the gynecologist or oncologist, clinical algorithms were developed to show important treatment pathways in simple flowcharts. Also, the definitions of quality targets and indicators were covered in the first S3 guideline. Indicators were set by reference regions and target values to define quality of processes and results. These were adopted as part of the quality management of the 'Deutsche Krebsgesellschaft (DKG)' and the 'Deutsche Gesellschaft für Senologie (DGS)' for the certification of German breast cancer centers.

\section{Methods}

The validity of this first version was limited to 2 years. Therefore, in spring 2006, the process of updating began. Besides the unchanged epidemiologic importance of breast cancer, new research results in particular were the basis for the revision. Also, the development of an accepted method to issue guidelines required editorial and content-related reworking of the existent medical guidance. The revised version was published in February 2008. Editor of the guideline is the 'Koordinierungszentrum für Standards in der Onkologie (ISTO) der Deutschen Krebsgesellschaft e.V.'. Different working groups, departments, and organizations participate as coeditors of the new guideline. All organizations that were involved in the development of the first version were also invited to support the update. They were asked to send out experts as representatives for the voting procedures, as well as to nominate experts for the discussion regarding content in working groups according to their specialization, to ascertain multidisciplinarity and professionalism. To fulfill international methodic require- ments [5], a systematic search of the literature with selection of new publications in the established data bases (Medline, BIOSIS, Previews, CDSR, ACP Journal Club, DARE, CCTR, CINHAL) was performed for the time period of 2003-2006. 10,094 papers could be identified, and after selection, 243 methodically resilient sources remained which could be used as evidences for the revision of the new guideline, on the basis of the Classes of Evidence of the Oxford Centre of Evidence Based Medicine. Furthermore, there was a systematic research of guidelines in the Guidelines International Network (GIN) which allowed matching with another 87 highlevel publications. Varied specialist opinions concerning diagnosis, therapy, and follow-up of breast cancer were considered in formal consensus processes. In different steps, Nominal Group Process (NGP) techniques, the Delphi technique, and formal consensus processes were used. Beside differently weighted, study-based recommendations, statements resulting from structured consensus finding by the interdisciplinary group - in terms of good clinical practice - were postulated [6].

\section{Results}

The final version consists of the following parts: After a general introduction which considers aspects of patient information, consent, and early detection, there are instructions for diagnosis and therapy of locoregional limited disease, recurrence, and metastatic breast cancer. Additionally, there is a new chapter called 'preinvasive lesions'. The chapters treating pathology and adjuvant radiotherapy were also completely revised. The former chapters of adjuvant and neoadjuvant treatment were structured differently. A new paragraph called 'therapy, support, attendance' places special emphasis on psycho-social aspects, as well as on rehabilitative and palliative care. The conception of the new guideline was accepted by the guideline group in October 2007 and adopted in December 2007 after another external re-evaluation. Besides the full version, a summary in German and English is in preparation. To back up the implementation, the full version will be available online under www.awmf.leitlinien.de, www.krebsgesellschaft.de, $w w w$. senologie.org, or www.g-i-n.net. In the following, important changes to and improvements of the new version are outlined.

\section{Familial Breast Cancer}

The new guideline places a focus on women whose breast cancer risk is higher due to an inherited genetic change. Patients affected by a mutation of one of the predisposing genes, BRCA1 and BRCA2, have a lifelong risk of $50-80 \%$ to suffer from breast cancer, $60 \%$ for a contralateral breast cancer, and $10-40 \%$ for ovarian cancer. Based on this epidemiologic situation, there are new recommendations for consultation and genetic tests. A multidisciplinary consultation and a genetic test should be offered in specialized centers if a family includes: i) at least 3 women suffering from breast cancer; ii) 2 women suffering from breast cancer and one is younger than 50 years; iii) at least 2 women suffering from ovarian cancer; iv) 1 woman suffering from breast and ovarian cancer; v) 1 women suffering from breast cancer under or at the age of 35 years; vi) 1 woman suffering from bilateral breast cancer under or at 
the age of 50 years; vii) 1 man suffering from breast cancer and one woman suffering from breast or ovarian cancer. The genetic test is based on a comprehensive consultation in a specialized and interdisciplinary department. If a woman with a mutation in the BRCA1 or -2 gene develops breast cancer, further therapy is the very same as for sporadic breast cancer. Thereby, the rate of ipsilateral secondary carcinoma is not elevated - according to present data - so that breast-conserving surgery is possible in the first-line therapy. A contralateral mastectomy can be performed to reduce the risk of a contralateral secondary carcinoma, but there is no evidence for longer survival rates. There are only some first data on this issue, which makes definitive recommendations impossible. Bilateral ovariectomy reduces the risk of secondary carcinoma of the breast and the ovaries. The typical histopathology and immunohistochemical phenotypes were described in an evidenced-based statement to encourage pathologists to be alert to a possible hereditary background of cancer in the future: BCRA1-associated breast cancer frequently are invasive carcinomas with a growth pattern similar to the medullary carcinoma. They express a G3 morphology and are estrogen receptor-negative, progesterone receptor-negative and HER2-negative (= triple-negative).

\section{General New Therapeutic Strategies in Primary Disease}

The revised guideline emphasizes patient orientation with regard to breast surgery. As regards content, the breast preservation combined with adjuvant radiation is equal to a modified mastectomy in survival rates. However, indications for a radical mastectomy still include: extensive calcification of a malignant type, multicentric carcinoma, incomplete resection after a second resection, and inflammatory carcinoma. Newer indications for radical surgery are: cosmetically insufficient result of breast-conserving therapy and contraindications for radiation therapy. No longer mentioned are extensive associated intraductal carcinomas of $>4-5 \mathrm{~cm}$ as well as the lack of a radiation possibility.

Sentinel lymph node biopsy was established as conditional for the histological evaluation of lymph node involvement, and is now an integral part of the operative therapy of invasive breast cancer. Axillary dissection and sentinel node biopsy are equal with regard to local control, but there is less morbidity in sentinel node biopsy.

With regard to all systemic therapies, new statements for the immunotherapy were formulated: Patients with HER2 (immunohistochemical score 3 and/or fluorescent in situ hybridization (FISH)-positive) should be treated with trastuzumab for 1 year. This therapy is recommended either in combination with taxane or subsequent to an antracycline- (taxane-) containing therapy. Receptor-positive women should receive hormone therapy which should be started after chemotherapy. There is evidence that the 3rd generation aromatase inhibitors are more effective than tamoxifen in postmenopausal women. Depending on the individual risk, aro- matase inhibitors can be given for 5 years primarily, 2-3 years in turns, after 2-3 years of tamoxifen, or even for 5 years after 5 years tamoxifen.

\section{Supportive Therapy}

An integral part of therapy should be optimal supportive care (antiemesis, wigs). Therefore, the guideline requires that all patients should be informed of the possible adverse reactions of different therapeutics, and should be offered preventive options. Problematic toxicities should be anticipated and preferably avoided. Concerning unstoppable secondary effects, prophylactic therapy normally works better than therapy after manifestation. In the beginning of a new chemotherapy, concomitant diseases and risk factors for adverse reactions should be registered, and the therapy should be adapted accordingly. In antiemetic treatment of chemotherapy-induced nausea, the well adjusted therapy always should start before a new cycle of chemotherapy. Oral and intravenous application is of equal value. In cases of failure of first-line therapy with 5HT3 receptor antagonists, neurokinin 1 receptor antagonists, or dexamethasone, application of metoclopramide can be promising. Solely a priori treatment with benzodiazepine, diphenhydramine, promethazine, or olanzapine is indeed not recommended.

Since myelosuppression is an integral part of the cytotoxic effects of chemotherapy, the guideline advises the application of G-CSF preparations if the risk of febrile neutropenia is $>20 \%$, according to the council of NCCN, ASCO, and EORTC based on large randomized studies.

\section{Preinvasive Lesions}

The new guideline contains a distinct chapter covering the clinical approach to preinvasive lesions of breast cancer. More preinvasive lesions are diagnosed through improved diagnostics and the implementation of comprehensive mammographic screening in Germany, which detects microcalcifications and derangement of tissue architecture. Current data regarding the potential of malignancy or risk of disease progression in those lesions is equivocal. No clear evidence exists for therapy and management of these biologically heterogenous lesions. Therefore, it is of general importance to plan therapy and follow-up on an individual and patient-orientated basis in interdisciplinary conferences. Also, in the case of ductal carcinoma in situ (DCIS), the patient should be offered an individual therapy concept compliant with the guideline, after explaining the pros and cons of single therapies and combinations, including possible secondary effects following therapy and their influence on recurrence rates and the lacking influence on survival.

Therapy options are therapeutic excision after preceding interventional radiological diagnostics, therapeutic second resection after an open diagnostic excision, postoperative radiation therapy, and drug treatment. Surgical options include breast-conserving surgery or mastectomy with sentinel node 
biopsy and plastic and reconstructive surgery if appropriate. Sentinel node biopsy is recommended especially if mastectomy is performed because of wide extensive lesions, and if there is suspicion of occult invasion. Normally, general axillary staging for DCIS is unnecessary. Radiation therapy is only recommended for breast-conserving R0 resections and for R1 resection after mastectomy, which cannot be re-resected. The rate of non-invasive recurrences and invasive breast cancer is reduced significantly by radiation after an optimal surgical therapy.

According to current studies, younger women, women with high-risk lesions, and women with marginal resection $(<1 \mathrm{~cm})$ benefit the most from postoperative radiation therapy. Treatment of older women is more difficult, because of the lack of influence on survival rates and the uncertain benefit. As adjuvant medical therapy, an anti-estrogen treatment with tamoxifen can be given. At present, there are no sufficient data available for gonadotropin-releasing hormone ( $\mathrm{GnRH})$ analogue treatment of premenopausal women or the use of aromatase inhibitors in postmenopausal women or for chemo- or antibody therapy.

\section{Follow-Up and Patient-Centered Care}

The chapter on follow-up was completely revised in the new guideline. Individualized risk-adapted care of affected women is considered absolutely necessary. Whereas therapy options can be discussed on the basis of risk classifications (TNM stage, hormone receptor expression, growth factor receptors, age, etc.), there are still no evidence-based studies analyzing the individual risk-adapted follow-up. Comparison of survival of different breast cancer stages shows that survival depends on stage, which could lead to a risk-adapted management even in follow-up, but the established follow-up structure has not yet been modified. That is why patients with metastatic carcinoma are treated and guided just as women at low risk of recurrence.

Follow-up of breast cancer starts with completing local therapy. It consists of history taking, physical examination, medical counseling, and support. Also, in follow-up, intensive interdisciplinary care is required. Besides oncologists, for example, psycho-oncologists, physiotherapists, and oncologically trained nurses need to be involved. Women with completed breastconserving therapy, even in the absence of symptoms, need follow-up with machine-aided diagnostics (sonogram or mammogram) in the ipsilateral breast. The contralateral breast of all patients needs to be checked on a yearly basis. Breast cancer spreads mostly to the lung, bones, and liver. Staging should include chest X-rays, positron emission tomography (PET) scan, and abdominal sonography when cancer is detected. There is no evidence that intense follow-up with fixed dates for staging diagnostics of symptom-free patients leads to a better survival outcome.

Prospective randomized studies for a risk-related diagnostic follow-up program or for the integration of techniques like
PET, control of tumor markers, risk detection with gene chips, or tissue microarrays are not available at present. Furthermore, it is possible that patients can detect metastases between the follow-up consultations, particularly if they are trained in self-observation of persisting symptoms and of the affected breast. Laboratory and machine-aided diagnostics are recommended for clinical suspicion of recurrence or metastases. Such diagnostics are not routinely provided for symptom-free patients.

\section{Discussion}

Guidelines are only effective if their recommendations are followed appropriately in the individual patient treatment. Before use, they should be adapted to the individual case [7]. The transformation of the shown algorithms in clinical treatment strategies is part of the idea of comprehensive implementation. Indicators defining quality of processes and results are important factors in the evaluation of guideline application. The guideline is valid until 2010 when a new revision to adapt new scientific data will be written. A series of lectures on the $\mathrm{S} 3$ guideline will be held in selected locations in Germany to contribute to the propagation of the new contents. The recommendations of this guideline address all doctors and members of professional groups concerned with the care of breast cancer patients (gynecologists, general practitioners, radiooncologists, psychooncologists, physiotherapists, nurses), and all patients and their relatives. The participation of patients in decision-making should be developed and should be mentioned in guidelines. Therefore, specialized evidence-based independent patient information was initialized in cooperation with patient organizations and self-help groups.

\section{Conclusion and Important (Shortened) Examples of Guideline Recommendations}

The first revision of the German S3 guideline 'Diagnosis, Therapy, and Follow-Up of Breast Cancer' contains aspects of patient information, consent and early detection, statements for preinvasive lesions, diagnosis and therapy of locoregional limited disease, recurrence and metastatic breast cancer. New chapters called 'therapy, support, attendance' place special emphasis on psychosocial aspects, as well as on rehabilitative and palliative care.

\section{Familial Breast Cancer}

If a woman with a mutation in the BRCA1 or -2 gene develops breast cancer, further therapy is the very same as in sporadic breast cancer. Breast-conserving surgery and radiation is possible in first-line therapy. BCRA1-associated breast cancer frequently are invasive carcinomas with a growth pattern similar to the medullary carcinoma. They express a G3 morphology, 
and are estrogen receptor-negative, progesterone receptornegative, and HER2-negative (= triple-negative).

\section{Locoregional Breast Cancer}

As regards content, breast preservation combined with adjuvant radiation is equal to modified mastectomy in survival rates. Sentinel lymph node biopsy was established as a condition for a histological evaluation of lymph node involvement, and is now an integral part of surgical therapy of invasive breast cancer.

\section{Pre-Invasive Lesions}

No clear evidence exists for the therapy and management of these biologically heterogeneous lesions. Therefore, it is of general importance to plan therapy and follow-up on an individual and patient-orientated basis in interdisciplinary confer- ences. Surgical therapy includes breast-conserving surgery and mastectomy with sentinel node biopsy.

\section{Adjuvant Therapy}

Receptor-positive women should receive hormone therapy after chemotherapy. Patients with HER2 (immunohistochemical score 3 and/or FISH-positive) should be treated with trastuzumab for 1 year, combined with or after chemotherapy.

\section{Follow-Up}

Patients with metastatic carcinoma are treated and guided just like women at low risk of recurrence. All statements and recommendations are available online under www.awmf. leitlinien.de, www.krebsgesellschaft.de, www.senologie.org, and www. g-i-n.net.

\section{References}

1 Giersiepen K, Heitmann C, Jahnsen, Lange C: Brustkrebs; in Robert-Koch-Institut (ed): Gesundheitsberichterstattung des Bundes. Berlin, RobertKoch-Institut, 2005.

2 Selbmann HK, Kopp I: Implementierung von Leitlinien in den Versorgungsalltag. Psychiatrie 2005;1:33-38.

3 Kreienberg R, Kopp I, and members of the guideline group: Interdisziplinäre Leitlinie für die Diagnostik und Therapie des Mammakarzinoms der Frau. München, Zuckschwerdt, 2004.
4 Lorenz W, Ollenschläger G, Geraedts F, Gerlach F, Gerlach A, Gangjour A, Helou H, Kirchner M, Koller W, Lauterbach H, Reinauer H, Sitter H, Thomeczek C: Das Leitlinien Manual: Entwicklung und Implementierung von Leitlinien in der Medizin. ZaeFQ 2001;95:1-84.

5 Scottish Intercollegiate Guidelines Network: SIGN 50: A Guideline Developer's Handbook. Edinburgh, SIGN, 2001. www.sign.ac.uk/guidelines.
6 Delbecq AL, van de Ven AH, Gustafson DH: Group Techniques for Program Planning. Glenview, IL, Scott, Foresman and Company, 1975.

7 Europarat: Entwicklung einer Methodik für die Ausarbeitung von Leitlinien für opotimale medizinische Praxis. Empfehlung des Europarates und erläuterndes Memorandum. ZaeFQ 2002;96:1-60. 